\title{
SMARTKADASTER: OBSERVING BEYOND TRADITIONAL CADASTRE CAPABILITIES FOR MALAYSIA
}

Mohd Noor Bin Isa, Teng Chee Hua, Nur Zurairah Binti Abdul Halim

Cadastral Division, Department of Survey and Mapping Malaysia, Kuala Lumpur, Malaysia

KEYWORD: SmartKADASTER, JUPEM, Multipurpose Cadastre

\section{ABSTRACT:}

The digital age for cadastral surveying started in stages, more than 20 years ago in Malaysia and JUPEM played a vital role in its successful implementation nationwide. One of the key products of cadastral survey is cadastral maps, which provide useful information for any land information system. However, as technology evolved and simplicity is familiarised, better services are anticipated and have affected how cadastral survey information are perceived. A paradigm shift is necessary where enriched cadastral information is required for multiple usage and allow real cadastral information based services to users. On that note, JUPEM is intrigued to develop a system where National Digital Cadastral Database is value added with other geospatial information for a smart and multipurpose environment and clearly be interpreted as a decision making tool with the aids of 3D realistic spatial data, namely SmartKADASTER. The SmartKADASTER is an ongoing project developed by JUPEM with the aim to establish a realistic and SMART cadastral-based spatial analysis platform for an effective planning, decision making, enabling efficiencies and enhancing communication and management to support SMART services towards SMART City enablement in Malaysia. It is developed in phases with the Federal Territory of Putrajaya and Kuala Lumpur as the initial project implementation area. This paper provides awareness and insights of the on-going development of the project and how it could benefit potential users and stakeholders.

\section{JUPEM'S ROLE}

For more than 20 years, JUPEM plays a vital role in modernising and transforming the Cadastral Survey system in Malaysia. Among others, the eKADASTER system was introduced in 2010 and was implemented nationwide. It was developed by JUPEM based on the characteristics recommended by Cadastre 2014 (introduced by FIG in 1994) and managed to gain recognition nationally and internationally as a system that seeks to expedite the cadastral survey delivery system. However, in line with current IT trends of mobility, social media, big data, Internet of things and cloud technology as well as the introduction of the eKADASTER system, a paradigm shift is needed in order to remain relevant to the nation in providing Cadastral Survey based services. Furthermore, the idea of extending Cadastral information to meet other new requirements and Beyond Cadastre (Rohan et.al, 2014), especially for better and accurate geospatial analysis should be realised, in line with contemporary trends and the needs of globalization. In addition, as technology evolves and data acquisition becomes friendlier, the move towards traditional cadastre into a multipurpose environment concept has come to be inevitable.

\section{COMPLEXITY OF CADASTRAL INFORMATION}

As one of the leading geospatial agency and geospatial data provider in Malaysia, JUPEM is anticipated to continuously be at par with the current geospatial trends and finding use in high impact sectors, by extending the usage of traditional cadastral information for a multipurpose environment. In today's GIS based system, the Cadastral survey information provides cadastral base maps for spatial analysis. However, due to different coordinate systems, coordinate projections and GIS formats, accurate geospatial analysis based on cadastral base maps is difficult and complex to grasp. The intricacy to achieve the desired vertical information in Mean Sea Levels too hinders the implementation of accurate vertical geospatial analysis. In addition, most geospatial analysis is improbable without the realistic (real world) details or object's relationship with its land parcel. And although 3D modelling are available for terrain modelling, 3D urban modelling or city modelling with cadastral information is not yet available in Malaysia. On that note, JUPEM is intrigued to develop a system where National Digital Cadastral Database is value added with other geospatial information for a smart and multipurpose environment and clearly be interpreted as a decision making tool with the aids of $3 \mathrm{D}$ realistic spatial data, namely SmartKADASTER.

\section{SMARTKADASTER'S KICK OFF}

SmartKADASTER is an on-going project under the Malaysia's 10th Development Plan (RMK10) to value add the accurate National Digital Cadastral Database with other geospatial information for a smart and multipurpose environment. It involves a paradigm shift of cadastral Information access to cadastral information based services. This project was initiated in 2014 with the aim to establish a realistic and SMART Cadastralbased spatial analysis platform for an effective planning, decision making, enabling efficiencies and enhancing communication and management to support SMART services towards SMART City enablement in Malaysia. It is conducted in phases with the Federal Territory of Putrajaya and Kuala Lumpur as the initial project implementation area.

The development of the SmartKADASTER was assured after an unanimous agreement was made during a client/user engagement program on 26 February 2014 between JUPEM and 10 other departments (Jabatan Pengairan Dan Saliran, Jabatan Penilaian dan Perkhidmatan Harta, Jabatan Alam Sekitar, Dewan Bandaraya Kuala Lumpur, Jabatan Bomba dan 
Penyelamat, Jabatan Perangkaan, Jabatan Kerja Raya, Jabatan Kastam Diraja Malaysia, Perbadanan Putrajaya dan Jabatan Mineral dan Geosains) as follows:

i. Users agreed with SmartKADASTER project implementation to be developed by JUPEM;

ii. Users will support data sharing between agencies / departments and strengthen the workforce for this project ;

iii. This project will help strengthen the existing GIS system available in various agencies / departments;

iv. Implementation of this project will help various agencies / departments on accurate spatial decision making; and

v. Users agreed pictometry aerial oblique and additional data that will be captured including Cadastral survey data in this project will assist a more accurate data interpretation and visualization.

\section{THE GIST OF SMARTKADASTER}

The essence of SmartKADASTER (as per Figure 1) is mostly adopting the Cadastre 2.0 concept (Gerda, 2012), proposed by FIG and later enhanced by JUPEM by infusing local requirements to the concept such as recommendations from the previously known Multipurpose Cadastre (MPC) feasibility project with the latest IT trends, 3D enabled surveying equipment technologies and Web 3.0 users requirement which are mainly inclined to having information fast, simple, mobile and are geolocation literate.

One of the game-changing trends that JUPEM has to acknowledge is the fusion of geospatial analytics with content derived from multiple data sources and devices. For the purpose of value adding Cadastral survey information and improve spatial data interpretation, components such as building footprint, street addresses, oblique photogrammetry, panoramic images and laser point clouds are utilised in the project to meet the characteristics SmartKADASTER. Among the characteristics of SmartKADASTER are as shown in figure 1 .

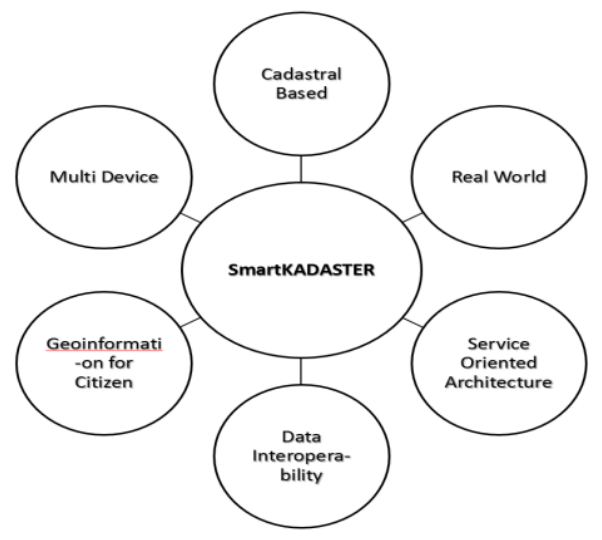

Figure 1 Characteristics of SmartKADASTER
To integrate all these multi sources, a lightweight application that is scalable, portable and dynamic is required, allowing it to be deployed and visualised in web browsers, mobile device and various desktop platforms. On that note, SmartKADASTER is to be developed with the same intention for the easiness of users / clients with the introduction of SmartKADASTER Interactive Portal or SKiP in short as shown in Figure 2.

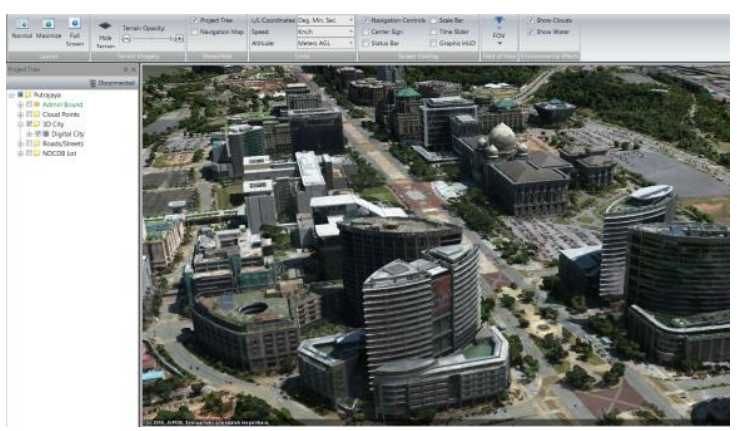

Figure 2 A snapshot of SKiP 3D View of FT Putrajaya

\section{SMARTKADASTER INTERACTIVE PORTAL (SKIP)}

One of the main products available via SKiP is the 3D Digital City Modelling of the FT Kuala Lumpur and Putrajaya. The 3D City Modelling is to be developed by leveraging 3D datasets produced from either airborne or terrestrial available 3D survey technologies as to meet the demands of 3D representation of building that has becoming ubiquitous and the desired amount of detail is no longer limited to geometrics but including semantic information of the façade. SmartKADASTER's new capabilities advance JUPEM's abilities to maintain and publish current Cadastral Survey data while maintaining a rigorous historic record of how the same has changed and clearly be interpreted as a decision making tool with the aids of other 3D spatial data. Studies have shown that representing the data visually creates a more compelling user experience and geospatially tagging data enhances location-specific intelligence which enables user to gain new insights and make faster decisions.

SKiP will provide a comprehensive set of analysis, exploration and design tools for all data types to allow users to make smart decision and the opportunity to conduct simulations such as rise of water level, shadow analysis, best terrain path and etc, based on 3D terrestrial modelling and city modelling. Via SKiP too, a crowd sourcing concept will be introduced to update and comment existing information with new or additional verified information to encourage government and public or community collaboration.

New functions are also introduced in SKiP that covers data sharing and dissemination via Service Oriented Architecture (SOA) that allows real time SmartKADASTER database access which will complement existing user's GIS system or enhancing legacy application capabilities and enable new 
applications for smart and accurate spatial analysis development as shown in Figure 3.

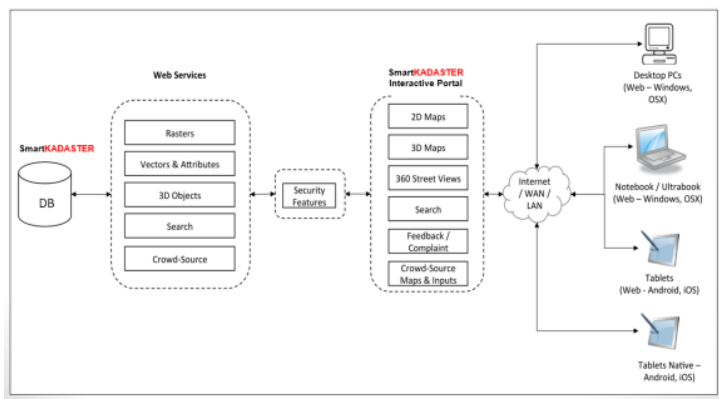

Figure 3 SmartKADASTER Data Sharing \& Dissemination Flow

\section{SMARTKADASTER CURRENT STATUS AND FUTURE IMPACT}

To date, the SmartKADASTER project has completed its Provisional Acceptance Test (PAT) stage for FT Putrajaya and Kuala Lumpur implementation and is scheduled to be fully operative by early 2016 . A beta version of SKiP will be made available in November, 2015 for further comments and engagement.

SmartKADASTER is expected to benefit all levels of governments and society as an integral part of sustainable development. The other benefits of SmartKADASTER extends to support Malaysia's National Key Result Area in property inventory, infrastructure project implementation and monitoring, event planning, crime preventions but most of all as an accurate cadastral based spatial decision making tool for analysis, planning and monitoring purposes, including disaster management and analysis such as flood analysis, as shown in Figure 4.

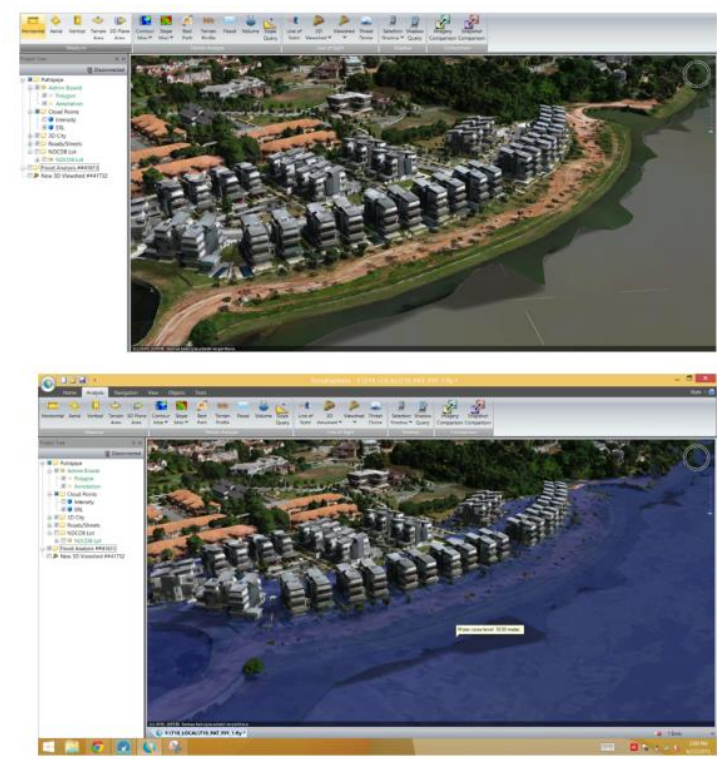

Figure 4 Flood anlysis based on 3D City Model of FT Putrajaya via SKiP
SmartKADASTER is also anticipated as a ground breaker for 3D Cadastre enablement in Malaysia that shall cover the air, marine and multilevel spaces with the mean sea level as the corresponding vertical datum. It will also be a tool to help Land Administrator to identify and determine the rights, restriction and responsibility on the particular 3D parcel.

On that note, SmartKADASTER is an initiative by JUPEM to enable beyond traditional cadastre implementation, with the emphasis are being made to service oriented, rather than product based.

\section{CONCLUSION AND FUTURE PLAN}

Although the Malaysian government vigorously supports land administration related projects, the challenge is for JUPEM to evolve strategies and structures such that it is well poised to continue to serve the needs of the nation and remain relevant. At the end of the day, a total paradigm shift has to be made in JUPEM's business process where the move from information access towards information services should be implemented and SmartKADASTER will be one of its means of implementation. It is JUPEM's vision to implement the SmartKADASTER concept all over the nation, in phases and continues its development within the 11th Malaysian Development Plan to address new challenges and demands including implementation of 3D geospatial data representation.

\section{REFERENCES}

Teng Chee Hua \& Nur Zurairah Binti Abdul Halim, Beyond eKADASTER; Kertas Persidangan Pengarah 2014, JUPEM

Dato' Hasan Jamil, Dr Mohd Yunus Mohd Yusoff \& Nur Zurairah Binti Abdul Halim, Implementing Multipurpose Cadastre in Malaysia; Coordinates Jun Edition, 2014

G. Schennach, Austria (2012), - Land Management in Cadastre 2.0 surroundings; FIG Working Week 2012

Rohan Bennett, Mohsen Kalantari, and Abbas Rajabifard - Beyond Cadastre 2014; University of Melbourne, Australia 